\title{
Targeted Therapy with Rituximab in Felty's Syndrome: A Case Report
}

\author{
Line Heylen ${ }^{1}$, Daan Dierickx ${ }^{2}$ Peter Vandenberghe ${ }^{3}$ and René Westhovens ${ }^{*}, 1$ \\ ${ }^{1}$ Rheumatology, ${ }^{2}$ Haematology and ${ }^{3}$ Human Genetics, University Hospital Leuven, Leuven, Belgium
}

\begin{abstract}
Felty's syndrome is a rare, severe extra-articular manifestation of rheumatoid arthritis (RA). There is no standard therapy, and several disease-modifying antirheumatic drugs have been used with varying success. Only very few reports exist in literature on the use of biologicals in this indication and this with a variable efficacy. We report the case of a 53-year-old woman with severe refractory/partly undertreated RA who presented with Felty's syndrome and pancytopenia, in whom treatment with rituximab led to an marked increase of red blood cells, neutrophils and thrombocytes. In addition, the RA disease activity status improved dramatically and treatment with steroids could be reduced. The current sparse literature on this topic is reviewed.
\end{abstract}

Keywords: Felty's syndrome, Rituximab, rheumatoid arthritis.

\section{INTRODUCTION}

Felty's syndrome is a rare but severe extra-articular manifestation of rheumatoid arthritis (RA), in most cases developing after a longer refractory disease course. The syndrome is defined as a triad of RA, neutropenia and splenomegaly [1]. Due to recurrent infections, patients with Felty's syndrome have an increased mortality, with a 5-year mortality rate of up to $36 \%[2,3]$. To treat Felty's syndrome, various disease-modifying antirheumatic drugs have been used with mixed success and few data are available on the use of biologicals that might even increase the infection risk. Because of the rarity of the disease, definite efficacy and safety results from biological therapies are not expected to become available in the future. Few case reports in the literature deal with the use of rituximab which might be seen as a preferred treatment in RA patients with major systemic features. We report on a severe refractory and partly undertreated RA patient with Felty's syndrome and discuss her successful treatment with rituximab. Oral consent was obtained from the patient to report her evolution anonymously.

\section{CASE REPORT}

A 53-year old Caucasian woman with a 22-year history of refractory rheumatoid factor and CCP positive RA was referred to our University Hospital in October 2010 because of a 2-year history of pancytopenia and hepatosplenomegaly, diagnosed as Felty's syndrome and a very severe disease activity status of her RA. In addition, she was known with arterial hypertension and an allergy to penicillin. She smoked $>30$ pack years but stopped smoking a few years ago. Epilepsy was diagnosed in 1992 after a generalized tonic-clonic seizure, for which she was treated with phenytoin and primidone. Previous therapies for RA

*Address correspondence to this author at the Rheumatology, UZ KU Leuven, Herestraat 49, 3000 Leuven, Belgium; Tel: +32-16-342541;

Fax:+32-16-342543; E-mail: rene.westhovens@uzleuven.be consisted of sulphasalazine and intermittent glucocorticoids. Methotrexate in recent years was never considered because of pancytopenia. A bone marrow biopsy was performed in the referring hospital in 2009 , showing only mild dysmegakaryocytosis and a modest decrease of the white blood cell maturation. Treatment with sulphasalazine was temporarily interrupted because of this pancytopenia. Because of persisting pancytopenia, hepatosplenomgaly and enlarged axillary and mediastinal lymph nodes on computer tomography of the chest, a lymph node biopsy was done beginning of 2010 which showed follicular hyperplasia and no evidence of lymphoma. Meanwhile she was on oral glucocorticoid therapy but a severe polyarthritis persisted and purpura on the lower limbs appeared clinically compatible with rheumatoid vasculitis. Treatment with topical steroids and hydroxychloroquine was added, the dose of glucocorticoids was increased and the patient was referred to our third care referral centre.

She presented in our hospital with an active destructive polyarthritis and large RA nodules, with a disease activity score (DAS28) of 4.7 while on methylprednisolone $16 \mathrm{mg}$, hydroxychloroquine $200 \mathrm{mg}$, sulphasalazine $2000 \mathrm{mg}$ and piroxicam $20 \mathrm{mg}$ daily. In addition, she was treated with phenytoin and primidon for epilepsy, acebutalol and furosemide for hypertension, pantoprazol for oesophagitis as well with escitalopram $10 \mathrm{mg}$ and lormetazepam. Her spleen was enlarged $(17 \times 11 \mathrm{~cm})$, as well as her liver $(19 \mathrm{~cm}$ craniocaudal diameter). She had purpura on the lower limbs and a diffuse lymphadenopathy, with follicular hyperplasia on biopsy. Study of her files revealed a white cell count remaining persistently less than $1.0 \times 10^{9} / 1$ and a hemoglobin level below $10.9 \mathrm{~g} / \mathrm{dl}$. Thrombocytes decreased continuously during the last year, and were less than $20 \times 10^{9} / 1$ at presentation in our hospital. A new bone marrow biopsy showed some hypocellularity without dysplasia, no blast cells and a normal central lymphocytosis without atypia. Immunophenotyping showed no monoclonal B- or T-cell process. Hydroxychloroquine and sulphasalazine were stopped. Methylprednisolone was maintained at $16 \mathrm{mg}$ daily 
and a treatment with rituximab was started twice $1000 \mathrm{mg}$ over 2 weeks in November 2010, and again twice $1000 \mathrm{mg}$ $\left(588 \mathrm{mg} / \mathrm{m}^{2}\right)$ in July 2011. DAS score dropped from 4.7 to 3.0, 17 months after treatment start. CRP decreased from 41 $\mathrm{mg} / \mathrm{L}$ to $7 \mathrm{mg} / \mathrm{L}$, and the erythrocyte sedimentation rate (ESR) decreased from $73 \mathrm{~mm} / \mathrm{h}$ to $32 \mathrm{~mm} / \mathrm{h}$. An overview of the evolution of DAS and the pancytopenia in the first year of follow up is presented in Fig. (1). The number of red blood cells, neutrophils and thrombocytes increased significantly: hemoglobin from $10.9 \mathrm{~g} / \mathrm{dl}$ to $15.1 \mathrm{~g} / \mathrm{dl}$, white blood cells from $0.81 \times 10^{9} / \mathrm{L}$ to $3.92 \times 10^{9} / \mathrm{L}$ and thrombocytes from $18 \times 10^{9} / \mathrm{L}$ to $120 \times 10^{9} / \mathrm{L}$. Interestingly the hypergammaglobulinemia dropped from $23.9 \mathrm{~g} / \mathrm{l}$ at treatment start to $19.2 \mathrm{~g} / 1$ and $15.8 \mathrm{~g} / 1,6$ and 18 months after treatment initiation. Patient was satisfied as also pain, general well being and quality of life dramatically improved. From month 4 on gradually tapering of glucocorticoids was initiated and 1 year after start of rituximab she was on $6 \mathrm{mg}$ daily. There were no infections within the first treatment year and planned foot surgery because of severe deformities could be performed without any problem.

\section{DISCUSSION}

We report an important beneficial effect of rituximab in a patient with Felty's syndrome, without immediate side
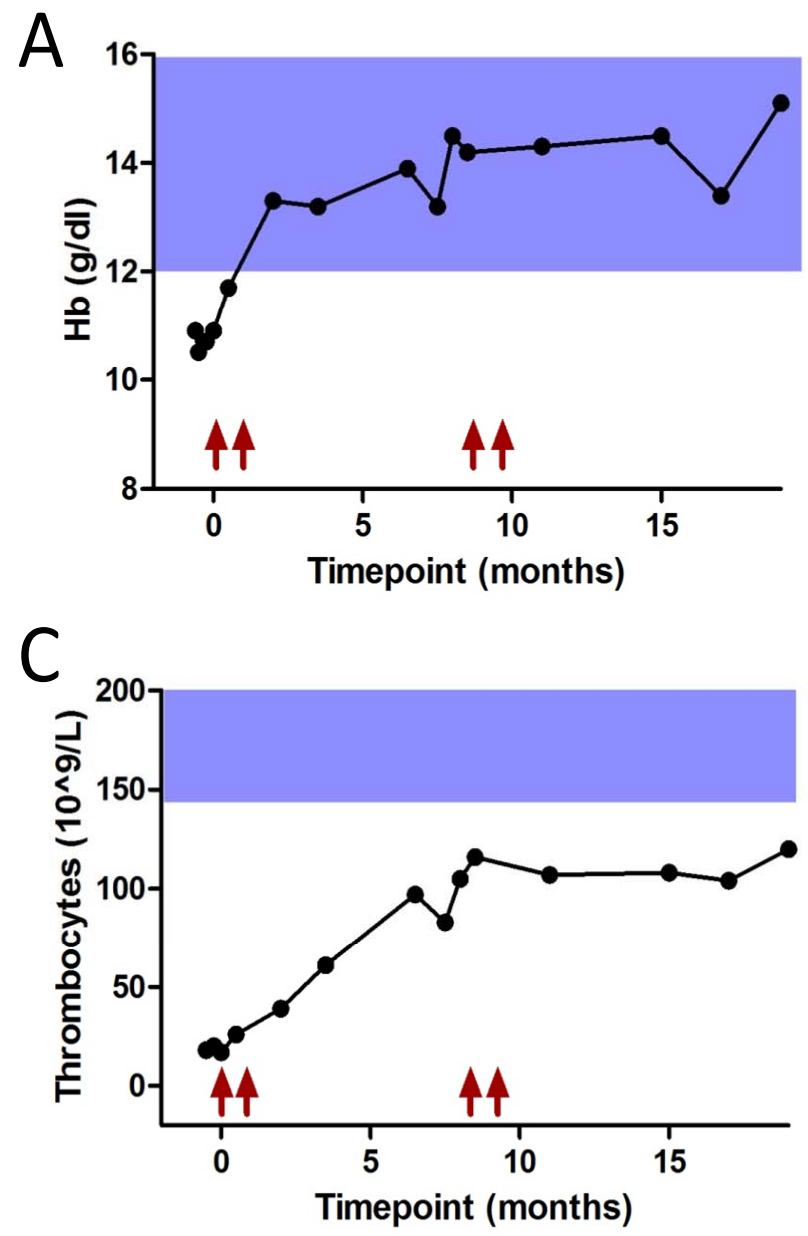

effects. Both the arthritis and the hematological features of the syndrome were much better controlled by 4 months after therapy start and steroid tapering was successful. The purpura on the lower limbs did not reoccur and there were no infectious complications.

Rituximab is chimeric monoclonal antibody against CD20, which is expressed on the surface of B-lymphocytes, causing B-cell depletion. It was originally developed for the treatment of B-cell lymphoma [4,5]. As T-cell activation is classically described as the key component of the pathogenesis of rheumatoid arthritis (RA), the efficacy of rituximab in RA came initially as a surprise. In 1999 Protheroe et al. wrote a case in which a patient with erosive arthritis was treated with rituximab for a B-cell lymphoma [6]. Following this treatment, the patient unexpectedly became free of musculoskeletal symptoms and joint inflammation. The role for B-cells in RA was later confirmed in randomised controlled studies, in which response rates of $51 \%$ and $85 \%$ were noticed with rituximab $[7,8]$.

While the immunopathogenesis of RA becomes further unraveled, Felty's syndrome remains still a mystery. Traditionally, splenomegaly was seen as a feature of systemic inflammation, causing neutropenia by sequestration
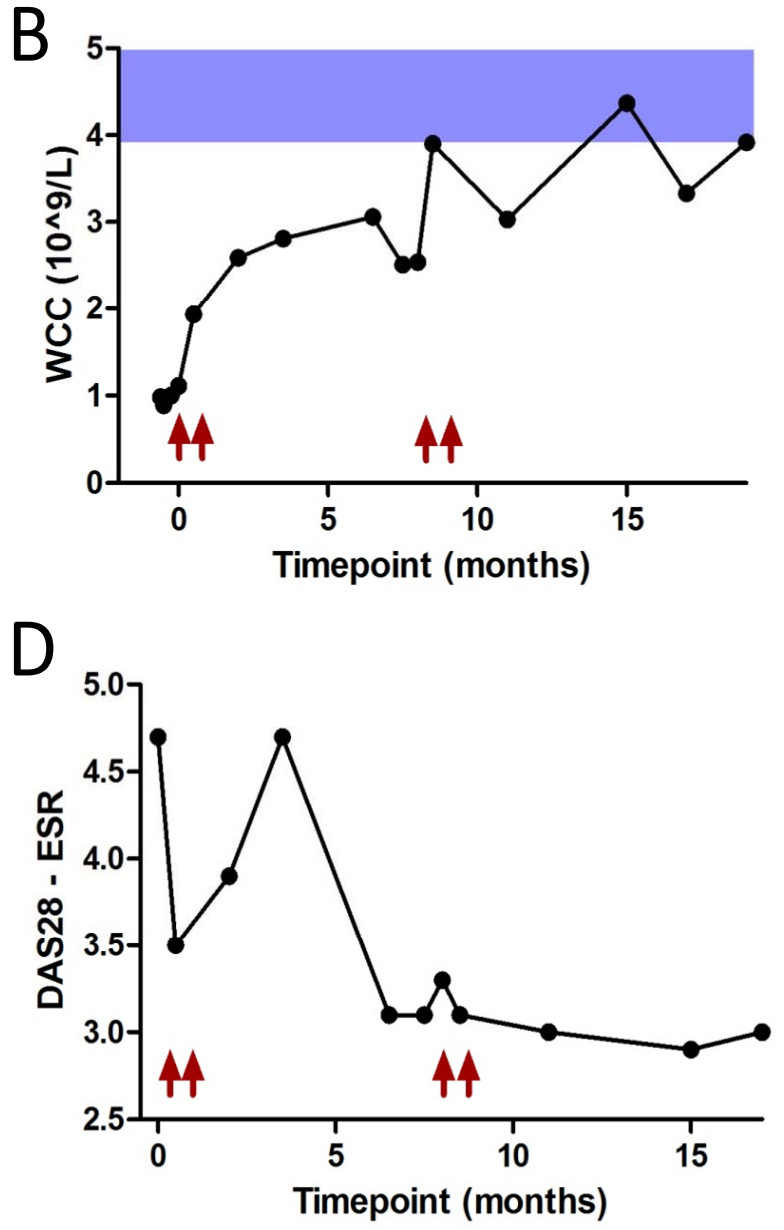

Fig. (1). The evolution of hemoglobin (Hb) (A), white cell count (WCC) (B), thrombocytes (C) and the DAS28 score (D) up to 19 months after therapy start. Arrows indicate time of Rituximab infusions. 
and justifying splenectomy as treatment. When Gupta et al. described reduced colony-stimulating activity in the serum of patients with Felty's syndrome [9], a role for impaired regulation of granulopoiesis became recognized in addition to peripheral destruction or sequestration (hypersplenism) as cause of neutropenia. As Felty's syndrome is an autoimmune disease, the loss of immunologic tolerance to self-antigens can cause neutropenia through both peripheral immunological destruction and impaired granulopoiesis. This is traditionally described as a cell-mediated destruction. However, humoral immunity might be important as well in causing neutropenia. Humoral suppression of normal granulopoiesis has been reported [10], as well as serum antibodies against mature neutrophils [11]. The antibody production against circulating neutrophils and against granulopoiesis can be suppressed by B-cell depletion, providing a rationale for the use of rituximab. However, the role of B-cells in autoimmune cytopenias can not only be limited to the production of antibodies, as the efficacy of rituximab in certain conditions associated with antibodies, is not correlated with a reduction of these antibodies [12]. They could also play a role through the production of cytokines and by acting as antigen-presenting cells supporting the activation of autoreactive cells [13].

The use of rituximab in patients with Felty's syndrome is rarely mentioned in the literature. Weinreb et al. [14], Salama et al. [15] and Lekharaju et al. [16] described a beneficial response. In contrast, Sordet et al. described two cases of Felty's syndrome where rituximab lacked efficacy [17]. These varying results underscore the multifactorial pathogenesis of Felty's syndrome and could suggest the existence of subsets of patients where rituximab could be beneficial [16]. The exact role of rituximab in Felty's syndrome needs further investigation. In this particular case it should also been noted that methotrexate was never used in the past because of fear for the hematological status. In our opinion and according to literature, this therapy option might also be effective in Felty syndrome and whenever her disease would relapse in the future the addition of methotrexate will be considered [18].

\section{CONCLUSION}

This observation contributes in the absence of randomized controlled data to the understanding of the role of specific biological therapies as rituximab in rare immune mediated disorders and appeals to further collaborative studies to increase robustness of data in these challenging situations.

\section{CONFLICT OF INTEREST}

The authors confirm that this article content has no conflicts of interest.

\section{ACKNOWLEDGEMENTS}

Declared none

\section{REFERENCES}

[1] Balint GP, Balint PV. Felty's syndrome. Best Pract Res Clin Rheumatol 2004; 18: 631-45.

[2] Campion G, Maddison PJ, Goulding N, et al. The Felty syndrome: a case-matched study of clinical manifestations and outcome, serologic features, and immunogenetic associations. Medicine (Baltimore) 1990; 69: 69-80.

[3] Thorne C, Urowitz MB. Long-term outcome in Felty's syndrome. Ann Rheum Dis 1982; 41: 486-9.

[4] Maloney DG, Grillo-Lopez AJ, Bodkin DJ, et al. IDEC-C2B8: results of a phase I multiple-dose trial in patients with relapsed non-Hodgkin's lymphoma. J Clin Oncol 1997; 15: 3266-74.

[5] McLaughlin P, Grillo-Lopez AJ, Link BK, et al. Rituximab chimeric anti-CD20 monoclonal antibody therapy for relapsed indolent lymphoma: half of patients respond to a four-dose treatment program. J Clin Oncol 1998; 16: 2825-33.

[6] Protheroe A, Edwards JC, Simmons A, Maclennan K, Selby P. Remission of inflammatory arthropathy in association with antiCD20 therapy for non-Hodgkin's lymphoma. Rheumatology (Oxford) 1999; 38: 1150-2.

[7] Edwards JC, Szczepanski L, Szechinski J, et al. Efficacy of B-celltargeted therapy with rituximab in patients with rheumatoid arthritis. N Engl J Med 2004; 350: 2572-81.

[8] Cohen SB, Emery P, Greenwald MW, et al. Rituximab for rheumatoid arthritis refractory to anti-tumor necrosis factor therapy: Results of a multicenter, randomized, double-blind, placebo-controlled, phase III trial evaluating primary efficacy and safety at twenty-four weeks. Arthritis Rheum 2006; 54: 2793-806.

[9] Gupta R, Robinson WA, Albrecht D. Granulopoietic activity in Felty's syndrome. Ann Rheum Dis 1975; 34: 156-61.

[10] Duckham DJ, Rhyne RL Jr, Smith FE, Williams RC Jr. Retardation of colony growth of in vitro bone marrow culture using sera from patients with Felty's syndrome, disseminated lupus erythematosus (SLE), rheumatoid arthritis, and other disease states. Arthritis Rheum 1975; 18: 323-33.

[11] Wiik A, Munthe E. Complement-fixing granulocyte-specific antinuclear factors in neutropenic cases of rheumatoid arthritis. Immunology 1974; 26: 1127-34.

[12] Cooper N, Arnold DM. The effect of rituximab on humoral and cell mediated immunity and infection in the treatment of autoimmune diseases. Br J Haematol 2010; 149: 3-13.

[13] Dierickx D, Delannoy A, Saja K, Verhoef G, Provan D. Anti-CD20 monoclonal antibodies and their use in adult autoimmune hematological disorders. Am J Hematol 2011; 86: 278-91.

[14] Weinreb N, Rabinowitz A, Dellaripa PF. Beneficial response to rituximab in refractory Felty Syndrome. J Clin Rheumatol 2006; 12: 48 .

[15] Salama A, Schneider U, Dorner T. Beneficial response to rituximab in a patient with haemolysis and refractory Felty syndrome. Ann Rheum Dis 2008; 67: 894-5.

[16] Lekharaju V, Chattopadhyay C. Efficacy of rituximab in Felty's syndrome. Ann Rheum Dis 2008; 67: 1352.

[17] Sordet C, Gottenberg JE, Hellmich B, Kieffer P, Mariette X, Sibilia J. Lack of efficacy of rituximab in Felty's syndrome. Ann Rheum Dis 2005 ; 64: 332-3.

[18] Allen LS, Groff G. Treatment of Felty's syndrome with low-dose oral methotrexate. Arthritis Rheum 1986; 7: 902-5. 